\title{
A DIFÍCIL TAREFA DE COMPREENDER OS ARRANJOS ESPACIAIS CONTEMPORÂNEOS
}

\author{
Ana Maria Nicolaci-da-Costa \\ Pontifícia Universidade Católica do Rio de Janeiro, Rio de Janeiro, Brasil
}

\begin{abstract}
RESUMO: Ao longo da história, tempo e espaço mantiveram uma relação estável e equilibrada. Com a descoberta do vapor e de outras fontes de energia inanimada, nos séculos XVIII e XIX, há uma profunda mudança nesse quadro. O tempo é acelerado e essa aceleração se torna uma das principais características da modernidade. Nas últimas décadas do século XX, acontece outra transformação radical na relação tempo/ espaço. As novas tecnologias de informação e telecomunicação, os transportes cada vez mais rápidos e a derrubada de fronteiras modernas instauram a era da instantaneidade, dos novos espaços virtuais e da fácil circulação de informação, pessoas e bens. Novos arranjos espaciais subvertem os existentes na modernidade; o espaço ganha proeminência. O presente artigo examina reflexões e pesquisas feitas sobre os espaços contemporâneos e oferece uma colaboração teórica calcada nos resultados de uma pesquisa sobre o uso de um conjunto de espaços virtuais e físicos por jovens brasileiros.
\end{abstract}

PALAVRAS-CHAVE: tempo; espaço; modernidade; contemporaneidade.

\section{THE HARD TASK OF COMPREHENDING THE CONTEMPORARY SPACE ARRANGEMENTS}

ABSTRACT: Throughout history, time and space maintained a stable and balanced relationship. With the discovery of steam and other sources of inanimate energy, in the $18^{\text {th }}$ and $19^{\text {th }}$ centuries, this picture changes dramatically. Time is accelerated and its acceleration becomes one of the central distinctive features of modern age. In the last decades of the $20^{\text {th }}$ century, there is another radical transformation in the time/space relationship. The new information and telecommunication technologies, the increasingly faster means of transportation and the disappearance of many modern frontiers generate an era of instantaneous communication, virtual spaces and easy circulation of information, people and goods. New space arrangements which subvert the modern ones emerge; space becomes prominent. The present paper examines already published reflections and researches on contemporary spaces. It also offers a theoretical contribution based on the results of an investigation into the use of a host of virtual and physical spaces by young Brazilians.

KEYWORDS: time; space; modern age; present days.

Ao longo dos séculos, tempo e espaço mantiveram uma associação estável. Espaço era aquilo que homens, mulheres e crianças podiam atravessar com maior ou menor rapidez utilizando recursos básicos, como as próprias pernas ou as pernas de um animal. Em contrapartida, tempo era aquilo de que se necessitava para percorrer um determinado espaço fazendo uso desses mesmos recursos (Bauman, 2000/2001).

Na passagem do século XVIII para o XIX, a utilização do vapor como fonte de energia inanimada dá início à mecanização, acelera o tempo e põe fim a essa estabilidade. Surgem meios de transporte que reduzem progressivamente a duração dos deslocamentos espaciais. Surgem, ainda, outras fontes de energia e outras tecnologias, algumas das quais, como o telégrafo e o telefone, geram a aceleração-limite do tempo e tornam o espaço irrelevante ao permitirem o contato instantâneo entre pessoas distantes.
Na visão de diversos autores (Bauman, 2000/2001; Harvey, 1989/1999; Sennett, 1998/1999), essa profunda alteração na tradicional associação tempo-espaço é um dos elementos constitutivos do período moderno. Bauman chega a declarar que "a modernidade começa quando o espaço e o tempo são separados da prática da vida e entre si, e assim podem ser teorizados como categorias distintas e mutuamente independentes..." (Bauman, 2000/2001, pp. 15-16).

Na modernidade, tal separação resultou no predomínio do tempo sobre o espaço, pois, ".... a modernidade é, talvez mais que qualquer outra coisa, a história do tempo" (Bauman, 2000/2001, pp. 128-129). Na contemporaneidade, porém, isso muda.

Nas últimas décadas do século XX, o avanço das tecnologias de telecomunicação - ainda caracterizado primordialmente pela integração de diferentes pontos do mundo via satélite - permite que a aceleração-limite 
do tempo, já atingida de forma restrita no período moderno, se alastre. É inaugurada a era da instantaneidade e da integração multinacional. Como consequência, as concepções de tempo e espaço sofrem uma nova mudança radical que, para muitos (entre os quais, Bauman, 1997/1998, 2000/2001; Harvey, 1989/1999, Jameson, 1984, ${ }^{1}$ 1991/1997; Sennett, 1998/1999; Virilio, 1984/1999), marca o fim do período moderno.

Nessa nova era, como afirma Jameson, "nossa vida cotidiana, nossas experiências psíquicas, nossas linguagens culturais [passam a ser] dominadas pelas categorias de espaço e não [mais] pelas de tempo" (Jameson, 1991/1997, p. 43). Como resultado, as novas concepções de espaço ganham proeminência nos debates sobre as características do mundo de hoje. E, mesmo antes da vertiginosa difusão das sofisticadas tecnologias de informação e telecomunicação contemporâneas (principalmente da Internet e da telefonia celular), ocorrida a partir de meados da década de 1990, alguns autores já se preocupavam com a nossa - humana incapacidade de pensar os novos espaços pelos quais transitamos e nos quais vivemos.

Jameson e Augé são dois bons exemplos. Jameson refere-se à "incapacidade de nossas mentes... de mapear a enorme rede global e multinacional de comunicação descentrada em que nos encontramos presos" (Jameson, 1991/1997, pp. 70-71). Já Augé afirma que “vivemos num mundo que ainda não aprendemos a olhar. Temos que reaprender a pensar o espaço" (Augé, 1992/2001, p. 37).

\section{Repensando o espaço}

As duas últimas décadas do século XX e a primeira do século XXI vêm presenciando muitas tentativas de repensar o espaço. Estas partem de pontos de vista diferentes e independentes, formando um cenário pouco integrado. Várias, no entanto, encontram um mesmo obstáculo para a apreensão das complexidades dos espaços em que vivemos nos dias de hoje: a dificuldade de abandonar as concepções modernas nas quais fomos socializados.

Grosso modo, pode-se dizer que tais tentativas dizem respeito a dois momentos principais. O primeiro corresponde aos esforços de apreensão e compreensão das alterações introduzidas no espaço físico pela crescente rapidez dos transportes e pela instantaneidade das comunicações via satélite. Já o segundo abarca as tentativas de captação principalmente das consequências do surgimento de um espaço virtual autônomo - aquele gerado pela interconexão dos computadores mundiais - e das alterações ocorridas no espaço físico em função da difusão da telefonia móvel.

A seguir serão brevemente apresentadas algumas dessas análises já detidamente discutidas em outro trabalho (Nicolaci-da-Costa, 2005). Sua exposição respeitará esses dois momentos e, dentro de cada um, será organizada em função da cronologia de publicação. Feito isso, serão destacadas as principais tendências que perpassam essas diferentes reflexões em ambos os momentos.

\section{A Cronologia de Diferentes Análises}

Ainda na década de 1980, Deleuze \& Guattari (1980/1997) argumentam que, para entender as mudanças pelas quais estão passando nossas sociedades, é necessário pensar as mudanças espaciais que a elas estão vinculadas. Para fazer isso, propõem as categorias de espaço "liso" e "estriado" como metáforas para diferentes tipos de organização e dinâmica sociais. A seu ver, o espaço "estriado" se assemelha a um tecido com suas tramas de fios verticais e horizontais que se entrecruzam. É, portanto, emblemático da organização e do funcionamento sociais do sistema capitalista da era moderna, marcados que estes eram por certezas, barreiras ou fronteiras. Já o espaço "liso", dizem, se assemelha ao feltro, no qual não há distinção entre fios nem tampouco entrecruzamentos; há apenas um emaranhado de fibras. Embora liso, tal como o feltro, este espaço não é homogêneo. E mais, desconhece certezas, demarcações, limites, fronteiras, centros, direções. Induz ao nomadismo, à circulação, e é perfeito como metáfora para o período pós-moderno ou contemporâneo. ${ }^{2}$

Na mesma década, autores da chamada corrente pós-modernista, como Jameson (1984, 1991/1997), Virilio (1984/1999), Harvey (1989/1999) e Augé (1992/2001) também mostram estar preocupados com as novas organizações espaciais, com a queda de barreiras e fronteiras e com a crescente circulação de pessoas e bens.

Jameson discorre sobre um "hiperespaço" tão novo e multifacetado que "consegu[e] ultrapassar a capacidade do corpo humano de se localizar, de organizar perceptivamente o espaço circundante e mapear cognitivamente sua posição em um mundo exterior mapeável" (Jameson, 1991/1997, p. 70). Virilio vê a instantaneidade como geradora de diversos tipos de "poluição" espacial, a principal das quais é o encolhimento do mundo. Harvey (1989/1999) afirma que, na pós-modernidade, a velocidade e a instantaneidade têm como resultado a quase completa aniquilação dos obstáculos espaciais. A seu ver, contudo, nem todos têm sua mobilidade aumentada. Os capitalistas se tornam altamente móveis dado que o capital desconhece fronteiras e pode arcar com os custos de meios de transporte velozes e sistemas de telecomunicação sofisticados. Os trabalhadores, no entanto, permanecem presos aos seus territórios. Augé (1992/2001) identifica um paradoxo: se, por um lado, o mundo encolheu em virtude da aniquilação do espaço, por outro, está havendo uma superabundância espacial causada pelas mudanças de escala a partir das quais tempo e espaço são medidos. Tal superabundância, por 
sua vez, gera consideráveis modificações físicas, como as novas formas de nomadismo (para ele, não restritas à elite capitalista) e a proliferação de lugares de passagem (os “não-lugares").

A vertiginosa difusão das tecnologias de informação e telecomunicação na década de 1990 introduz outro importante elemento nesse cenário: um espaço alternativo ao físico. Entre os pós-modernistas, Bauman $(1997 / 1998,2000 / 2001)$ é o primeiro a reconhecer a existência de tal espaço. Entretanto, talvez sob o efeito da concepção de mobilidade diferenciada de trabalhadores e capitalistas de Harvey, para Bauman, esse novo espaço "extraterritorial" não passa de uma espécie de "bolha", frequentada pelas elites mundiais, cujas características próprias não se dedica a analisar. Tal como no caso dos outros pós-modernistas já mencionados, seu interesse continua preso às alterações no espaço físico. Nesse sentido, dá concretude ao nomadismo sugerido pela metáfora do espaço "liso" de Deleuze e Guattari ao enfatizar a "fluidez" da movimentação de pessoas e coisas acarretada pela derrubada das fronteiras e barreiras modernas. Registra, também, a emergência de novos arranjos espaciais resultantes da crescente mobilidade de tudo e todos (a exemplo dos "não-lugares" mencionados por Augé).

Uma vez difundida a Internet, aparecem outras formas de pensar o espaço por ela gerado. Diferentemente da tendência pós-modernista de enfatizar o encolhimento do mundo (físico), vários autores começam a ressaltar a amplitude e a autonomia em relação às leis da física do novo espaço virtual (Wertheim, 2001).

Castells denomina esse novo espaço de espaço dos "fluxos", dado que ele se organiza em torno de "práticas sociais de tempo compartilhado por meio de fluxos" (1996/2000, pp. 436-437). A fluidez é, portanto, registrada em uma nova dimensão (desta feita tecnológica). Para ele, o espaço dos fluxos é tão importante que domina e molda a nova organização social contemporânea, a da "sociedade em rede".

"Espaço dos fluxos" não é, no entanto, a nomenclatura mais difundida para fazer referência ao espaço gerado pela conexão em rede dos computadores mundiais. Muitos preferem se referir ao "ciberespaço". 3 Para Lévy (1990/1993), um de seus mais conhecidos analistas, Internet e ciberespaço são a mesma coisa: um espaço autônomo no qual a humanidade passou a viver parte da vida.

Novos rearranjos do espaço físico e um novo espaço virtual para a vida cotidiana não esgotam, contudo, a gama de espaços aos quais temos acesso diariamente. $\mathrm{O}$ quadro se torna ainda mais complexo quando é levado em conta o hibridismo físico-móvelvirtual dos espaços produzidos pela telefonia celular. Então, temos que aguçar nossa sensibilidade e tornar ainda mais flexíveis nossas formas de pensar de modo a captar arranjos espaciais singulares característicos do nosso tempo. Vejamos.

A principal propriedade da telefonia celular é certamente a sua capacidade de conectar, instantaneamente, diferentes pontos do espaço físico independentemente da mobilidade dos interlocutores e/ ou da distância que os separa. Esta conectividade, por sua vez, produz uma fluidificação do espaço físico que vem sendo identificada por diversos pesquisadores (Ito \& Okabe, 2003; Kopomaa, 2000; Ling, 2004; Mäenpäa, 2001). Isso quer dizer que a fluidez virtual como que se acopla ao espaço físico e o transforma, aumentando de modo radical a mobilidade das pessoas já detectada anteriormente. Em outras palavras, de posse de nossos celulares, podemos fluir por um espaço híbrido, um espaço físico que pode a qualquer momento ser conectado ao virtual por meio de comunicações via celulares.

Outra importante mudança produzida pela telefonia celular é a produção de espaços privados virtuais móveis, que fazem com que muitos estudiosos se refiram ao celular como um "lugar", adjacente, porém fora do espaço doméstico, público ou do trabalho (Kopomoaa, 2000; Nicolaci-da-Costa, 2005); um lugar para o qual se pode fugir para bater papo sobre qualquer assunto (Puro, 2002).

\section{Principais Tendências Encontradas nessas Diferentes Análises}

Essa breve revisão da literatura revela que há pouco consenso entre os autores que vêm se dedicando a estudar os espaços contemporâneos. Sob os primeiros impactos da difusão da comunicação via satélites e da popularização de meios de transporte sempre mais ágeis, muitos falam do "encolhimento do mundo", sendo que alguns, tais como Augé e Virilio, veem tal encolhimento como a "aniquilação do espaço". A partir de diferentes óticas, no entanto, mesmo nesse primeiro momento, a tendência mais frequente - encontrada, por exemplo, em Deleuze e Guattari, Harvey e Bauman - é a de enfatizar a crescente mobilidade, ou "fluidez", de tudo e de todos em virtude da derrubada de fronteiras e barreiras antes existentes.

O contraste entre esse primeiro cenário e aquele que emerge após a entrada em cena da Internet e da telefonia celular é grande. Enquanto que antes se falava no encolhimento do mundo (físico), passa-se a enfatizar a amplitude do espaço gerado pela Internet (que se subdivide numa miríade de espaços) e a fluidez de circulação de tudo que não é material que ele permite. Já no que diz respeito à telefonia celular, começa-se a falar de espaços privados virtuais e, principalmente, da fluidificação do espaço físico acarretada pelo frequente uso dos celulares. 
Apesar da complexidade de toda essa discussão, é interessante observar que duas linhas de raciocínio principais nela estão constantemente presentes. A elas correspondem tendências aparentemente antagônicas nos modos de conceber os espaços contemporâneos.

A primeira dessas tendências se expressa por meio da constatação de que, se analisados independentemente, a partir de suas características únicas, os espaços contemporâneos são múltiplos. São muitos os espaços físicos pelos quais circulamos, são muitos os espaços (i.e. ambientes, plataformas e congêneres) gerados pela internet, são muitos os espaços conectados ou gerados pela telefonia celular. Tendo em vista a já mencionada dificuldade de abandonarmos concepções modernas, tal multiplicidade, por seu turno, parece pressupor que alguma linha divisória - membrana, barreira ou fronteira - separa esses espaços uns dos outros (não importa que estes sejam físicos, virtuais ou híbridos).

Em contrapartida, vários dos estudos discutidos na seção anterior defendem uma visão que se opõe a esta. Mesmo que recorram a diferentes nomenclaturas, autores tão diferentes como Deleuze e Guattari, Bauman, Harvey, Ling, Mäenpäa, Kopomaa e Ito e Okabe revelam a existência de um mesmo fenômeno. Para eles, a queda, ou diluição, de muitas das inúmeras membranas, fronteiras e barreiras (características do período moderno), que anteriormente insulavam diferentes áreas da experiência, também incide sobre os espaços contemporâneos. Em consequência, estes sofrem um processo de alisamento. A contemporaneidade seria, portanto, dominada por aquele que Deleuze e Guattari chamaram de "espaço liso", no qual nossa movimentação está se tornando cada vez mais fácil, ou "fluida" para usar a terminologia de Bauman.

Esse é o quadro que se apresenta a partir do que dizem aqueles que pensam os espaços contemporâneos. Resta saber qual a percepção que têm desses mesmos espaços aqueles que simplesmente vivem neles. Do que será que estes se dão conta?

\section{Pesquisa}

De modo a procurar respostas para essa pergunta, foi realizada uma pesquisa com jovens que, desde tenra idade, estão acostumados a circular com assiduidade por diversas vertentes de todas as três grandes categorias de espaço (físicos, virtuais e híbridos). A intenção era a de fazer um levantamento o mais detalhado possível das percepções que eles têm tanto do espaço físico quanto dos espaços pelos quais circulam ao fazerem uso das novas tecnologias de informação e comunicação, com as quais estão sempre muito familiarizados. Para tanto, como será discutido abaixo, recorreu-se a essas próprias tecnologias para o levantamento de dados.

\section{Metodologia}

Em todas as suas etapas, a presente pesquisa foi norteada pelos princípios e procedimentos do Método de Explicitação do Discurso Subjacente - MEDS (Nicolaci-da-Costa, 2007; Nicolaci-da-Costa, RomãoDias, \& Luccio, 2009)

O MEDS - especificamente elaborado para esse tipo de estudo exploratório - é um método qualitativo cuja coleta de dados é feita principalmente por meio de entrevistas abertas em contextos informais. Tendo em vista que contextos informais existem tanto na vida "real" quanto na "virtual", essas entrevistas podem ser levadas a cabo a partir de entrevistas face a face ou de entrevistas online (Nicolaci-da-Costa et al., 2009). No caso desta pesquisa, foi feita a opção pelas últimas.

\section{Participantes}

O recrutamento dos participantes foi feito de acordo com os seguintes critérios: (a) todos os participantes deveriam ser estudantes entre 18 e 25 anos, pois estes são usuários de praticamente todas as tecnologias disponíveis no mercado; (b) todos os jovens deveriam pertencer às camadas médias ou altas porque o acesso a essas tecnologias pode ser dispendioso; (c) todos os participantes deveriam minimamente ter celular próprio e fazer uso de um computador residencial; (d) todos deveriam residir na cidade do Rio de Janeiro, local de realização da pesquisa. Restrições a sexo ou profissão foram julgadas desnecessárias.

Com base nesses critérios, foram selecionados 20 jovens a partir de indicações de amigos e conhecidos. A todos foram atribuídos nomes fictícios para a preservação de seu anonimato. Sua média de idade era de 21 anos.

\section{Coleta de Dados}

A coleta de dados foi realizada por meio de entrevistas individuais realizadas online (Nicolaci-da-Costa et al., 2009) através do popular programa de bate-papo em tempo real MSN Messenger. O uso de entrevistas online tornou a pesquisa interessante e natural para os participantes e permitiu que fossem investigados aspectos de seu uso de diferentes espaços que não poderiam ter sido levantados por meio de entrevistas presenciais convencionais. Os entrevistados dominavam as ferramentas de bate-papo e demonstraram estar muito à vontade.

Todas as entrevistas foram baseadas em um roteiro estruturado (Nicolaci-da-Costa, 2007) construído especialmente para a pesquisa. Esse roteiro era composto por itens a partir dos quais deveriam ser formuladas as perguntas durante a própria entrevista de modo a 
preservar as características de conversas informais. Embora estruturado, o roteiro era usado de forma flexível durante as entrevistas, o que significa dizer que a ordem dos itens podia ser alterada de modo a manter o fluxo de associações do entrevistado (Nicolaci-daCosta, 2007).

O roteiro era dividido em duas partes. A primeira era composta de perguntas objetivas sobre cada um dos participantes, tais como: idade, o que estudava, há quanto tempo usava a Internet e há quanto tempo usava celular.

Já a segunda parte era composta por itens/perguntas de cunho mais investigativo e subjetivo. Esses itens se baseavam na observação dos hábitos que os jovens têm de usar, constante e no mais das vezes simultaneamente, diferentes tecnologias - interativas ou não - que lhes facultam o acesso a diferentes tipos de espaço. Intencionalmente, no entanto, nesses itens nenhuma menção era feita a categorias espaciais. Queríamos investigar se estas surgiriam espontaneamente, o que indicaria que os entrevistados tinham consciência de seu trânsito por diferentes espaços.

Logo no início da entrevista, era solicitado que o entrevistado/a enviasse ao entrevistador (pelo próprio MSN ou por email) um print screen ${ }^{4}$ da tela de seus computadores para que pudéssemos examinar quantas janelas estavam abertas para quais programas (ou "ambientes"). O print screen servia como disparador da entrevista.

Seguiam-se perguntas calcadas nos itens do roteiro, quase sempre acompanhadas de perguntas de aprofundamento (por quê?, como?, quando?, onde? e semelhantes), que podiam ser introduzidas sempre que necessário. Do roteiro faziam parte 22 itens e vários subitens sobre o uso de diferentes tecnologias. Dentre eles, os relevantes para a presente discussão eram: (a) o que o entrevistado/a tinha em volta do computador; (b) o que usava ao mesmo tempo em que o computador; (c) o que NUNCA usava ao mesmo tempo em que o computador; (d) em qual cômodo da casa estava; (e) onde estava seu celular; se tinha televisão por perto e se estava ligada; se o som estava ligado; se estava fazendo mais alguma coisa além de estar no computador; o que estava usando naquele momento no computador; se havia mudado alguma coisa desde o envio do print screen; (f) o que costumava usar ao mesmo tempo: computador, celular, telefone fixo, televisão, som, televisão, chat; como lidava com isso; (g) como se sentia fazendo várias atividades ao mesmo tempo no computador; (i) como se sentia fazendo várias atividades ao mesmo tempo fora dele; (j) com quantas pessoas costumava falar no MSN; caso o número variasse, a que se devia essa variação; naquele momento, com quantas pessoas estava falando além do entrevistador; (k) se falava no celular em lugares públicos; o que fazia para ter uma conversa íntima quando havia muita gente por perto; caso se afastasse, se achava que isso garantia a sua privacidade; (1) o que achava da lei que proíbe o celular enquanto a pessoa dirige; qual a dificuldade de falar no celular e dirigir ao mesmo tempo; qual a diferença entre falar, dirigindo, no celular e com uma pessoa ao lado; (m) qual a situação real que mais se assemelha ao: MSN, Orkut, e-mail, blog, fotolog.

\section{Análise dos Dados}

Todos os depoimentos foram salvos e copiados em arquivos do Microsoft Word para facilitar seu manuseio. Seguindo as técnicas do MEDS (Nicolacida-Costa, 2007), primeiramente foi levada a cabo a análise interparticipantes, na qual todas as respostas de todos os entrevistados/as foram reunidas a partir dos itens/perguntas feitos. As respostas a cada item foram analisadas como um bloco. Desse modo, obteve-se uma visão de conjunto que possibilitou a identificação e categorização das respostas recorrentes nos discursos dos entrevistados. Na segunda etapa - a da análise intraparticipantes - foram examinadas as respostas de cada um dos participantes em busca de possíveis inconsistências ou contradições reveladoras de algum discurso subjacente. Estas não foram encontradas. Nos depoimentos, havia somente os titubeios e reticências típicos de quem está falando sobre algo pela primeira vez. Assim sendo, os resultados abaixo têm como base somente a análise interparticipantes.

\section{Resultados}

Os depoimentos coletados mostram que os espaços físicos nos quais as entrevistas se desenrolaram eram muito semelhantes. Em praticamente todos os casos, os entrevistados estavam em seus próprios quartos, nos quais dispunham de inúmeros aparelhos interativos ou não - que lhes permitiam acesso a outros espaços. Para simplificar a presente exposição, estes serão chamados de "aparelhos-portais", pois abriam "portas" para outros espaços.

O computador e seus periféricos (como, por exemplo, a webcam e caixas de som) ocupavam um lugar central nesses quartos. Quase invariavelmente havia uma televisão, o celular, muitas vezes um telefone fixo e, algumas vezes, um rádio. Estes se misturavam a livros, CD's, ursinhos de pelúcia, câmeras fotográficas, ipods e congêneres, como acontece de praxe em quartos de jovens.

À guisa de exemplo, examinemos o que dizem dois dos entrevistados quando perguntados sobre o que havia em volta de seus computadores. ${ }^{5}$ 
Rafael revela ter "uma televisão, as caixinhas de som..., impressora, uma rede, $3 d v d s$, um livro de direito trabalhista e um pacote de camisinhas". E onde está seu celular? Rafael diz: "do meu lado...como sempre. pra não perder nenhuma ligação".

Em resposta à mesma pergunta, outra entrevistada, Gabriela, diz: "[o] telefone, fica bem do ladinho!!!". Acrescenta, ainda, "tem um ursinho..., o Wilson (meu cofre) e o Alemão (minha web cão), meu celular, meu radio, ipod, meu tel sem fio, $t v, d v d$ ".

Para identificar como eles lidavam com toda essa parafernália de modo a alcançar outros espaços a partir de seus quartos foi necessário estabelecer alguns critérios de agrupamento. Esses critérios nortearão a exposição abaixo.

\section{O que faziam nos computadores}

Os print screens que nos foram enviados eram bastante reveladores. Mostravam claramente que eles estavam conectados a vários espaços distintos a partir de seus computadores. Fazendo uso das já consolidadas metáforas concebidas pela Microsoft para a plataforma Windows, nas barras de tarefas que apareciam nesses print screens estavam registradas as "janelas" que eles haviam aberto para diferentes "ambientes".

Os entrevistados tinham sempre várias janelas abertas. Em geral, estas lhes facultavam acesso a programas interativos como o MSN Messenger, a sites de relacionamento como o Orkut, aos espaços de trabalho do Word ou do Power Point, ao YouTube e a outros ambientes. Seguem-se alguns exemplos.

Durante a entrevista, Julia conversava com a entrevistadora e outras duas pessoas no MSN. Além disso, tinha abertos o Orkut, o Outlook, um site, o Windows Media Player e o Word. Joy falava com cinco pessoas no MSN, tinha abertos o Orkut, o Word e ouvia música no iTunes. Marcos tinha abertos uma pasta do Windows Explorer, o Windows Media Player, um site e conversava com nove pessoas pelo MSN.

Esses exemplos mostram que, no mínimo, eles ativamente usavam o MSN para se conectar ao entrevistador e a vários outros interlocutores que estavam em diferentes espaços físicos, espaços esses que, provavelmente, influenciavam suas conversas online. Mas, isso não era tudo. Eles também frequentemente "visitavam" os perfis de amigos no Orkut, "entravam" no espaço do Word ou do Power Point para fazer seus trabalhos para a faculdade, no YouTube para ver um vídeo ou ainda em qualquer outro ambiente dos vários que tinham aberto e/ou podiam abrir.

Ficou claro que, para a maior parte dos entrevistados, fazer várias coisas em ambientes diferentes no computador era a norma, e não a exceção. Julia, por exemplo, diz: "se eu NÃO estou fazendo tudo [ao mesmo tempo] ... aí me sinto meio entediada". Fernanda dá um testemunho análogo: "se tiver com menos coisa eu fico achando alguma coisa inutil pra fazer, ... ai [aí] abro o jogo de paciencia e coisas do tipo".

É deste "fazer tudo ao mesmo tempo" que os entrevistados têm consciência. A esmagadora maioria não parece se dar conta de que, para que possam fazer várias coisas "ao mesmo tempo" em diferentes ambientes, têm que entrar e sair de espaços distintos. Somente uma entrevistada - Priscilla - se referiu espontaneamente a estar em diferentes "lugares" no computador. Para ela, no mundo "real", "eh dificil estar em dois lugares ao mesmo tempo né! o q eh bem diferente no pc [computador] onde temos a sensação de estarmos virtualmente transitando por vários lugares ao msm [mesmo] tempo."

Quando solicitados a fazer comparações entre os ambientes mais usados na Internet e situações no mundo "real", alguns fizeram analogias com espaços diferenciados no mundo físico. Essas comparações, contudo, não foram nem majoritárias nem sistemáticas, o que parece novamente indicar uma ausência de percepção desses ambientes virtuais como espaços.

Para Priscilla, por exemplo, o MSN pode ser comparado a uma

praia ... tem aquela conversa no calçadão com quem $v c$ encontra casualmente q geralmente não dura mt tempo ..., tem aquele mergulho no mar com aquela sua beeeeeest [melhor amiga] $q v$ c consegue contar coisas secretas ... e aquele papo de um bando de gente torrando na areia ...!

Já o Orkut ela associa à famosa Rua das Pedras em Búzios. Diz:

tem um bando de genteeeeee $q v \mathrm{v}$ ve sempre, ... vc falaria com um ou outro (aqueles scraps [recados] básicos e simpáticos), tem aquelas pessoas $q$ vc toma aquelas tequilas e fica junto a night toda e como consequência disso altos depoimentooos, lembranças, homenagens...e tem aquele povo amigo do amigo, colega do peguete [espécie de "ficante"], q vc tem ali naquela rua (pág [página]) mas nem fala direito.

Nem todos os entrevistados, contudo, têm a capacidade de visualização de Priscilla. E-mails foram geralmente comparados a cartas. Os blogs não suscitaram nenhuma comparação com um espaço físico; a analogia mais comum foi com diários. Já os fotologs geraram uma única comparação com porta de boate. Segundo Francisco: "nego vai pra lá so pra ver a cara de todo mundo, nego fala um oi ouve uma ou duas frases e ja muda...".

\section{Uso Simultâneo do Computador e de Outros "Aparelhos-Portais"}

No espaço físico de seus quartos, não é somente no computador que os entrevistados realizam atividades 
múltiplas. Diversos aparelhos-portais são frequentemente utilizados junto com o computador, novamente sem que esses jovens demonstrem ter qualquer consciência de trânsito por espaços diferentes.

São muitos os participantes que mantêm a televisão ligada enquanto usam o computador. Rafael diz: "eu ligo $o$ pc [computador] e ligo a tv ao msm [mesmo] tempo sempre". Marcos revela que deixa a televisão ligada e fica "escutando programas de esporte, ou vendo jogo,... normalmente tem tv,pc e as vezes videogame ligado ao mesmo tempo...". Priscilla revela que a televisão "fica ligada, só por estar ligada msm [mesmo] e se o msn estiver pouco badalado eu dou uma atençãozinha de leve".

Dado que a TV não exige interatividade e atenção, ela pode ficar ligada ao fundo para ser assistida eventualmente. O mesmo não acontece com o celular e o telefone, que exigem que seus usuários deem atenção ao que neles se desenrola. Alguns abandonam o computador temporariamente para falar no celular ou telefone fixo. É o caso de Marcos, que deixa o computador para atender o celular ou o telefone fixo, ao passo que continua vendo televisão enquanto fala no celular ou telefone: "normalmente qndo [quando] eu to no cel [celular] eu saiu [saio] do pc [computador], e qndo desligo retorno ... tel fixo,eu tbm [também] saiu do pc ... tv eu so saiu se tiver passando jogo do vascao ahuhauha [riso] ... oou,algum filme... q eu queira ver."

Para outros, no entanto, o computador e o celular/ telefone podem ser conjugados, embora com alguma dificuldade. Patrícia, por exemplo, revela conseguir usar o celular e o computador ao mesmo tempo, mas acrescenta que "dói o pescoço". Rafael também aponta uma dificuldade de ordem motora para conjugar o uso do celular com o do computador: "fica meio dificil de usar o mouse, o teclado e o celular ao msm [mesmo] tempo, afinal só tenho duas mãos...rs ... mas em geral é trankilo...rs ... soh digito mais devagar".

Não houve nenhum depoimento que indicasse alguma consciência da parte dos entrevistados de que os espaços gerados pelos celulares ou telefones e pelos computadores são bastante distintos e incompatíveis.

\section{Uso dos Celulares Fora de Casa}

Fora de casa, o celular substitui o computador como plataforma de interatividade à distância. Os depoimentos dos entrevistados indicam que ele é de fato usado como um espaço privado móvel sem que disso a maior parte deles pareça ter consciência.

Quando perguntados a respeito de como procediam para ter uma conversa íntima em lugares públicos, a maioria dos jovens revelou não gostar de ter conversas no gênero nessas circunstâncias. Mesmo assim, admitem que acabam conversando a respeito de assuntos privados no celular quando estão em público. Para tanto, contudo, dizem falar mais baixo e procurar um lugar mais calmo e/ou reservado.

Paula dá um excelente testemunho. Descreve um interessante processo de construção inconsciente de um espaço privado imaginário. Se há muita gente por perto, eis o que ela diz fazer: "saio de perto se possível ... se não, digo q ligo depois...". Paula sabe que se afastar não garante sua privacidade, mas admite que " $d a$ [dá] um sensação de q sim ... eh q parece q ninguém tah ouvindo sabe, igual a porta fechada...". Márcia revela usar procedimento análogo. Responde:

bom se eu estiver em um restaurante, bar etc......., peço licença e vou ao banheiro para ficar mais a vontade... agora se eu estiver onde não há banheiro, eu procuro um lugar mais calmo e vazio ... não garante [a privacidade], mas é a melhor forma quando se está em público!!

Paula e Márcia não estão sozinhas. Nos dias de hoje, podemos observar com frequência essa construção de algum tipo de divisória imaginária para separar um espaço temporariamente designado como privado daquele que é visivelmente público. Contudo, enquanto o comportamento é frequente, a consciência de que um espaço privado está sendo construído dentro de um espaço público, tal como Paula demonstra ter, não é.

\section{Dirigir e Usar o Celular}

As respostas às perguntas que lhes foram colocadas sobre a lei que proíbe o uso do celular quando se está dirigindo apresentaram resultados semelhantes. Poucos demonstraram ter alguma consciência de que parte do problema de dirigir e falar ao celular ao mesmo tempo advém do fato de que o celular leva o motorista para um outro espaço. A maioria atribuiu o perigo a uma dificuldade motora.

Esse é o caso de Rafael, que dá a seguinte resposta:

sendo o aparelho eu concordo...pq te faz tirar uma das mãos do volante (as vezes as duas qd tem q passar marcha) e isso diminui sua velocidade de reação...mas quanto ao blootooh [Bluetooth] não axo [acho] nada $d+$ [demais] usar ... o fato de estar falando ao telefone torna-se igual ao falar com alguém q estejo [esteja] no banco do carona ...

Marcos tem a mesma opinião. Revela: "acho correta, apesar de ngm [ninguém] respeitar ne...”. Quanto à diferença entre falar no celular e com a pessoa ao lado enquanto dirige, ele completa: "depende, se vc ta como celular na mao, tem diferença pois sua possibilidade de reacao eh meno [menor], agora se vc ta com o microfone pra mim $n$ [não] tem diferenca ... eh $u$ [o] mesmo $q$ escutar musica, a distração eh parecida."

Houve, no entanto, algumas vozes dissonantes. A de Clara foi uma delas. Ela afirma: acho [a lei] certa ... 
nao tem como se concentrar totalmente em duas coisas ... e o celular tira $m t$ [muito a] atençao..." Mesmo quando o motorista usa o viva-voz ou bluetooth? Clara diz: "sim... pq ve tem q se concentrar na conversa .. nao ha uma atneçao [atenção] total para o transito". E qual é a diferença entre falar no celular e conversar com a pessoa ao lado? A entrevistada responde: "a pessoa ao lado th estah acompanhando o trajeto e tal, eventualmente pode alertar caso aja algum perigo ou alguma situaçao q tenha q se agir rapido....pode 'ajudar'o motorista ... jah uma pessoa falando pelo cel nao pode fazer isso." Em outras palavras, o que Clara parece dizer é que motorista e passageiro estão no mesmo espaço.

\section{Discussão}

Antes de dar início à presente discussão, é importante relembrar as duas tendências aparentemente antagônicas nos modos de conceber os espaços contemporâneos que emergiram da revisão da literatura levada a cabo na primeira parte deste trabalho.

A primeira dessas tendências diz respeito ao fato de que, quando analisados a partir de suas características únicas, os espaços contemporâneos (que englobam os espaços físicos pelos quais circulamos, os espaços gerados pela Internet que frequentamos e os espaços gerados pela telefonia celular aos quais nos conectamos) são muitos. A visão de tal multiplicidade, por sua vez, repousa sobre a concepção moderna de que existem linhas divisórias - membranas, barreiras ou fronteiras - que separam esses espaços uns dos outros.

Já a segunda tendência se opõe à primeira na medida em que assevera que fronteiras, barreiras, membranas e outras formas de insulação, frequentemente encontradas na era moderna, já sofreram (ou estão sofrendo) alguma forma de alisamento. Em consequência disso, passamos a viver naquele que Deleuze e Guattari chamaram de "espaço liso", no qual nossa movimentação é "fluida", como diz Bauman, por não encontrar obstáculos.

Os resultados da pesquisa que acaba de ser apresentada indicam, contudo, que é possível propor uma terceira visão, na qual as duas primeiras podem ser parcialmente integradas sem conflito. Vejamos como chegamos a ela.

Se retornarmos aos estudos e pesquisas já descritos na análise da literatura relevante, constataremos que, em sua maior parte, eles consistem ou de reflexões teóricas feitas a partir da observação das transformações pelas quais vem passando o mundo em que vivemos, ou de análises de dados empíricos sobre o uso de espaços específicos.

Em ambos os casos, não são levadas em consideração, como foram na presente investigação, as experiências concretas que homens e mulheres têm com um conjunto de espaço(s) pelos quais circulam cotidianamente. E são exatamente essas experiências - ou melhor, o vivido cotidiano desses homens e mulheres - que sugerem a terceira visão mencionada acima. Para que possamos explicitá-la, faz-se necessário que retomemos os resultados que se sobressaíram nesta pesquisa. Passemos a eles.

Para começar, os jovens homens e mulheres entrevistados não mostraram ter consciência de que constantemente passavam de um espaço para outro ao longo das entrevistas que concederam. O que eles sistematicamente revelavam perceber era o fato de que realizavam tarefas múltiplas "ao mesmo tempo", sem que houvesse indícios de que registravam que muitas dessas tarefas eram executadas em espaços diferentes.

Isso faz sentido se considerarmos que, mesmo sem que o dissessem abertamente, os jovens entrevistados deixaram claro que circulavam livremente por um espaço no qual não havia fronteiras, barreiras ou outras linhas divisórias. Aqueles que, de acordo com a primeira visão, seriam os vários espaços abordados na pesquisa, para eles aparentemente já haviam sofrido o processo de alisamento descrito anteriormente, ou seja, já haviam se transformado no espaço "liso" de Deleuze e Guattari.

Tal constatação poderia sugerir que, na ausência de qualquer tipo de demarcação, esses espaços teriam perdido suas características únicas, gestadas no isolamento propiciado pelas linhas divisórias que os separavam anteriormente. Na realidade, no entanto, apesar da ausência de consciência de que estavam constantemente entrando e saindo de espaços distintos (mesmo que seu próprio discurso estivesse repleto de expressões como "entrar" e "sair" de "ambientes" ou "lugares"), os jovens entrevistados claramente conheciam as especificidades de cada um deles.

Se confrontados com o que diz a literatura especializada, tais resultados imediatamente geram a sensação de estarem parcialmente de acordo com as duas visões conflitantes descritas no início desta seção: aquela que enfatiza a multiplicidade dos espaços contemporâneos (ressaltando suas características únicas, mas implicitamente pressupondo linhas divisórias entre eles) e aquela que fala a respeito de um espaço liso (que pressupõe a extinção dessas linhas divisórias).

Uma reflexão mais aprofundada, no entanto, revela que essas duas visões simplesmente correspondem aos estados inicial e final de um processo ainda em andamento; um processo por meio do qual espaços com características distintas estão gradativamente deixando de ser separados uns dos outros por linhas divisórias ou barreiras rígidas, dado que estas estão progressivamente sendo diluídas ou derrubadas. Para alguns, notadamente para os "nativos digitais" 
(Prensky, 2001) que, como os nossos entrevistados, já cresceram em meio a video games, computadores, Internet, celulares e semelhantes, esse processo parece já estar concluído. Para outros, no entanto, ele pode se encontrar nos estágios iniciais. Este parece ser o caso daqueles que Prensky chamou de "imigrantes digitais", ou seja, daqueles homens e mulheres socializados no período moderno (entre os quais se encontram os autores mencionados ao longo deste artigo), para os quais a visão de mundo e a linguagem digitais pertencem a uma cultura para a qual migraram já adultos.

Interessante a ponto de merecer destaque é o fato de que, pelo menos para os jovens que entrevistamos, viver em um espaço liso não significa ignorar nem a multiplicidade nem a especificidade de espaços distintos. De sua ótica, parece realmente haver uma grande variedade de espaços com características únicas - muitos dos quais estavam frequentemente presentes nas suas falas - sem que estes sejam percebidos como separados por fronteiras ou quaisquer outras linhas divisórias que possam dificultar a passagem de um para outro. Para eles, a livre circulação por esses espaços é um mero dado de sua realidade; não requer nenhuma atenção porque simplesmente sua experiência lhes diz que "sempre foi assim".

Esses mesmos resultados mostram, também, que a complexidade da configuração espacial contemporânea depende muito da ótica que se adota para percebê-la. Como acaba de ser dito, tudo indica que para jovens como aqueles que participaram da pesquisa viver em um espaço liso composto por vários espaços com características singulares entre os quais não há fronteiras que dificultem a circulação é absolutamente natural. Eles parecem não ter nenhuma dificuldade em perceber que, como afirmavam Deleuze e Guattari (1980/1997), o espaço liso não é homogêneo.

Salvo raras exceções, como aquela que acaba de ser mencionada, esse não é, contudo, o caso de homens e mulheres mais velhos. Para esses - que conheceram o mundo a partir da ótica moderna das fronteiras rígidas e muitas vezes intransponíveis entre países, ideologias, sexos, gerações, horários e espaços - tudo isso é muito pouco natural e muito difícil de compreender. Para alcançar tal compreensão, a exemplo do que Augé (1999/2001) sugeriu, eles certamente têm que fazer um esforço consciente para aprender a pensar o espaço a partir de novas categorias.

E, dessas categorias, a principal - radicalmente nova para os mais velhos - talvez seja a de "fluidez". É a incapacidade de olhar o mundo a partir dela que provavelmente faz com que Jameson se refira a uma "incapacidade de nossas mentes ... de mapear a enorme rede global e multinacional de comunicação descentrada em que nos encontramos presos como sujeitos individuais" (Jameson, 1991/1997, pp. 70-71). Tal mapeamento - de- sejável e possível dentro da ordem do mundo moderno - se tornou impraticável na contemporaneidade pelo simples motivo de que aquilo que é fluido não produz estabilidade suficiente para ser mapeável.

\section{Notas}

1 As primeiras ideias sobre a lógica cultural do capitalismo tardio, inicialmente divulgadas em 1984, foram reimpressas em Jameson (1991/1997).

2 Esses dois tipos de espaço não se excluem mutuamente, apenas há o predomínio de um sobre o outro em determinados períodos.

3 Termo criado por William Gibson em uma obra de ficção científica intitulada Neuromancer (1984).

4 Um print screen é uma espécie de foto da tela do computador obtida pressionando a tecla "Print Screen" e posteriormente colando em outro ambiente como, por exemplo, no Word.

5 Os depoimentos que serão apresentados não sofreram nenhuma forma de edição. Foram preservadas todas as suas características originais, inclusive os inúmeros erros gramaticais e ortográficos e as inúmeras abreviações.

\section{Referências bibliográficas}

Augé, M. (2001). Não-lugares: introdução a uma antropologia da supermodernidade (M. L. Pereira, Trad.). Campinas: Papirus. (Trabalho original publicado em 1992)

Bauman, Z. (1998). O mal-estar da pós-modernidade (M. Gama \& C. M. Gama, Trads.). Rio de Janeiro: Jorge Zahar. (Trabalho original publicado em 1997)

Bauman, Z. (2001). Modernidade líquida (P. Dentzien, Trad.). Rio de Janeiro: Jorge Zahar. (Trabalho original publicado em 2000)

Castells, M. (2000). A sociedade em Rede (R. V. Majer, Trad.). São Paulo: Paz e Terra. (Trabalho original publicado em 1996)

Deleuze, G. \& Guattari, F. (1997). Mil platôs: capitalismo e esquizofrenia (Vol. 5, P. P. Pelbart \& J. Caiafa, Trads.). São Paulo: Editora 34. (Trabalho original publicado em 1980)

Gibson, W. (1984). Neuromancer. Berkeley: Ace.

Harvey, D. (1999). Condição pós-moderna (A. U. Sobral \& M. S. Gonçalves, Trads.). Rio de Janeiro: Loyola. (Trabalho original publicado em 1989)

Ito, M. \& Okabe, D. (2003). Mobile phones, Japanese youth and the re-placement of social contact. Acesso em 11 de dezembro, 2003, em http://www.itofisher.com/PEOPLE/mito/ mobileyouth.pdf

Jameson, F. (1984). Postmodernism, or the cultural logic of late capitalism. New Left review, 146, 53-92.

Jameson, F. (1997). Pós-modernismo: a lógica cultural do capitalismo tardio (M. E. Cevasco, Trad.). São Paulo: Ática. (Trabalho original publicado em 1991)

Kopomaa, T. (2000). Speaking mobile: the city in your pocket. Helsinki: Gaudeamus.

Lévy, P. (1993). As tecnologias da inteligência: o futuro do pensamento da era da informática (C. I. Costa, Trad.). Rio de Janeiro, Editora 34. (Trabalho original publicado em 1990)

Ling, R. (2004). The mobile connection: The cell phone's impact on society. San Francisco: Morgan Kaufmann. 
Mäenpäa, P. (2001). Mobile communication as a way of urban life. In A. Warde \& J. Gronow (Orgs.), Ordinary consumption (pp. 107-123). Londres: Routledge.

Nicolaci-da-Costa, A. M. (2005). O cotidiano nos múltiplos espaços contemporâneos. Psicologia: Teoria e Pesquisa, 21(3), 365-373.

Nicolaci-da-Costa , A. M. (2007). O campo da pesquisa qualitativa e o Método de Explicitação do Discurso Subjacente (MEDS). Psicologia: Reflexão e Crítica, 20(1), 65-73.

Nicolaci-da-Costa, A. M., Romão-Dias, D., \& Luccio, Flavia di (2009). O uso de entrevistas on-line no Método de Explicitação do Discurso Subjacente (MEDS). Psicologia: Reflexão e Crítica, 22(1), 36-43.

Prensky, M. (2001). Digital natives, digital immigrants. On the horizon, MCB University Press, 9(5), 1-6. Acesso em 07 de dezembro, 2008, em http://www.twitchspeed.com/ site/Prensky\%20-\%20Digital\%20Natives,\%20Digital\%20 Immigrants \%20-\%20Part1.htm

Puro, J.-P. (2002). Finland: a mobile culture. In J. E. Katz \& M. Aakhus (Orgs.), Perpetual contact: Mobile communication, private talk, public performance (pp. 19-29). Cambridge: Cambridge University Press.

Sennett, R. (1999). A corrosão do caráter: conseqüências pessoais do trabalho no novo capitalismo (M. Santarrita, Trad.). Rio de Janeiro: Record. (Trabalho original publicado em 1998)
Virilio, P. (1999). Espaço crítico (P. R. Pires, Trad.). Rio de Janeiro, Editora 34. (Trabalho original publicado em 1984)

Wertheim, M. (2001). Uma história do espaço de Dante à Internet. Rio de Janeiro: Jorge Zahar. (Trabalho original publicado em 1999)

Ana Maria Nicolaci-da-Costa é Professora Associada do Departamento de Psicologia e Coordenadora do Núcleo de Estudos sobre Tecnologia e Subjetividade da PUC-Rio. Endereço para correspondência: PUC Rio. Rua Marquês de São Vicente, 225 - Gávea - 22543-900. Rio de Janeiro/RJ. Email: anicol@puc-rio.br

\section{A difícil tarefa de compreender os arranjos espaciais contemporâneos}

Ana Maria Nicolaci-da-Costa

Recebido em: 13/02/2009

Revisão em: 09/09/2009

Aceite final em: 23/11/2009 